\title{
Biodegradation of toluene by the new fungal isolates Paecilomyces variotii and Exophiala oligosperma
}

Elena Estévez, María C. Veiga, Christian Kennes

Journal of Industrial Microbiology and Biotechnology, January 2005, Volume 32, Issue 1, pp 33-37

DOI: $10.1007 / \mathrm{s} 10295-004-0203-0$

\begin{abstract}
Two new fungal strains, namely Paecilomyces variotii and Exophiala oligosperma, were isolated on toluene as the sole carbon and energy source, mineralizing the substrate into carbon dioxide. Fungal strains isolated so far on such a pollutant and completely degrading it are very scarce. Both fungi degraded the pollutant over the $\mathrm{pH}$ range 3.96.9 and temperature range $23-40^{\circ} \mathrm{C}$, but E. oligosperma was barely active at the highest temperature of $40^{\circ} \mathrm{C}$. Fungal growth on alkylbenzenes at $40^{\circ} \mathrm{C}$ has not been reported before. Since the activity of the strains gradually decreased at $\mathrm{pH}$ values below 4.0, the use of nitrate instead of ammonium was tested. In the presence of toluene, nitrate was a suitable nitrogen source for the Exophiala strain, but not for the Paecilomyces strain. Nitrate rather than ammonium allowed the maintenance of a more constant $\mathrm{pH}$.
\end{abstract}

\section{Keywords}

Alkylbenzenes, biofiltration, bioremediation, extremophiles, volatile organic compounds 


\section{Introduction}

Alkylbenzenes are common contaminants in soils, aquifers and waste gases. Together with benzene, they are among the most abundant aromatic compounds in gasoline and some other refined products obtained from crude oil. In addition, they are used in many industrial processes as solvents and they provide the starting material for the production of many other chemicals. Benzene and alkylbenzenes released into the environment are present at low concentrations (in the parts per million range) and are degradable by different bacterial species $[\underline{15}, \underline{16}]$.

The use of alkylbenzenes as sole carbon and energy sources in bacteria, which was demonstrated several decades ago, has been studied extensively in such organisms [1]. However, although the biodegradation of such pollutants is well documented in prokaryotes, a similar characteristic was not demonstrated in filamentous fungi until the mid-1990s, when a Cladosporium sphaerospermum strain was described for its ability to grow on toluene as sole carbon and energy source while completely mineralizing it [19]. As reviewed recently, only very few other fungal strains have been identified and isolated since then on alkylbenzenes [10]. White-rot fungi are also known to degrade volatile aromatic pollutants, although this is often a co-metabolic process in those organisms. Besides, the biodegradation of toluene in different strains of the white-rot fungus Phanerochaete chrysosporium led to only about 50\% mineralization in the best case [21].

The recently reported complete biodegradation of some aromatic volatile organic compounds (VOC) by a few filamentous fungi is an interesting discovery, not only for the progress of basic research but also for its potential application to the treatment of VOC-contaminated systems, in particular waste gases $[\underline{9}, \underline{10}]$. Indeed, it was recently shown that higher toluene removal efficiencies can be reached in biofilters in which filamentous fungi rather than bacteria are dominant $[\underline{4}, \underline{5}, \underline{9}, \underline{18}, \underline{20}]$. It is hypothesized that the filamentous structure of these eukaryotes allows for a rapid mass transfer of hydrophobic pollutants from the gas phase to the biocatalyst $[\underline{6}, \underline{9}]$. Besides, fungi are more resistant than most bacteria to extreme environmental conditions such as low $\mathrm{pH}$, reduced water content, etc. $[\underline{5}, \underline{9}, \underline{10}]$. Such characteristics are also interesting in soil bioremediation in environments hostile to bacterial activity [14].

In this paper, the isolation on toluene of two new fungal strains, Paecilomyces variotii and Exophiala oligosperma, with complete mineralization of the substrate, is reported. Their activity was evaluated at different temperatures and $\mathrm{pH}$ and with two different nitrogen sources. This is the first report on the biodegradation of this alkylbenzene by these fungal species and on the consumption of toluene at low $\mathrm{pH}$ and relatively high temperature $\left(40^{\circ} \mathrm{C}\right)$ in fungi.

\section{Materials and methods}

\section{Media composition}

Batch experiments were undertaken with an aqueous culture medium containing (per liter): $4.5 \mathrm{~g} \mathrm{KH}_{2} \mathrm{PO}_{4}, 0.5 \mathrm{~g} \mathrm{~K}_{2} \mathrm{HPO}_{4}, 2.0 \mathrm{~g} \mathrm{NH}_{4} \mathrm{Cl}$ and $0.1 \mathrm{~g} \mathrm{MgSO}_{4} \cdot \mathrm{H}_{2} \mathrm{O}$. The culture medium was autoclaved at $120^{\circ} \mathrm{C}$ for 20 min before adding filter-sterilized solutions of vitamins and trace minerals. The composition of the vitamins solution was (per liter): $0.2 \mathrm{~g}$ thiamine $\cdot \mathrm{HCl}, 0.1 \mathrm{~g}$ riboflavin, $1.0 \mathrm{~g}$ nicotinic acid, $2.0 \mathrm{~g}$ Ca-pantothenate, $0.1 \mathrm{~g}$ biotin, $0.1 \mathrm{~g}$ thioctic acid, $0.1 \mathrm{~g}$ folic acid and $0.25 \mathrm{~g}$ pyridoxine $\mathrm{HCl}$. The composition of the trace minerals solution was (per liter): $120 \mathrm{mg} \mathrm{FeCl}_{3}, 50 \mathrm{mg} \mathrm{H}_{3} \mathrm{BO}_{3}, 10 \mathrm{mg}$ 
$\mathrm{CuSO}_{4} \cdot 5 \mathrm{H}_{2} \mathrm{O}, 10 \mathrm{mg} \mathrm{KI}, 45 \mathrm{mg} \quad \mathrm{MnSO}_{4} \cdot \mathrm{H}_{2} \mathrm{O}, 20 \mathrm{mg} \quad \mathrm{Na}_{2} \mathrm{MoO}_{4} \cdot 2 \mathrm{H}_{2} \mathrm{O}, \quad 75 \mathrm{mg}$ $\mathrm{ZnSO}_{4} \cdot 7 \mathrm{H}_{2} \mathrm{O}, 50 \mathrm{mg} \mathrm{CoCl}{ }_{2} \cdot 6 \mathrm{H}_{2} \mathrm{O}, 20 \mathrm{mg} \mathrm{AlK}\left(\mathrm{SO}_{4}\right)_{2} \cdot 12 \mathrm{H}_{2} \mathrm{O}, 13.25 \mathrm{mg} \mathrm{CaCl}_{2} \cdot 2 \mathrm{H}_{2} \mathrm{O}$ and $10,000 \mathrm{mg} \mathrm{NaCl}$. The original $\mathrm{pH}$ of that medium was 5.9. The $\mathrm{pH}$ could be adjusted to another value either by modifying the mass ratio of the phosphate compounds while maintaining a constant concentration of potassium or, most often, by adding $\mathrm{NaOH}$ or $\underline{\mathrm{HCl}}$. When studying the effect of the nitrogen source, $\mathrm{NH}_{4} \mathrm{Cl}$ was replaced by $\mathrm{KNO}_{3}$.

Stock cultures of the fungi were maintained on Petri dishes or on slants using either potato dextrose agar (PDA) or the same mineral medium as described above supplemented with $16 \mathrm{~g} \mathrm{agar}^{-1}$. When using the mineral medium, the plates were incubated in a tank or desiccator at $30^{\circ} \mathrm{C}$, in the presence of toluene vapors as carbon source. Stock cultures on PDA were stored in a refrigerator at $4^{\circ} \mathrm{C}$.

\section{Alkylbenzene biodegradation in batch assays}

All assays were performed at least in duplicate, with the corresponding controls. Both uninoculated media (called "blanks") and inoculated autoclaved vials (called "controls") were used. The mineral medium described above $(200 \mathrm{ml})$ was introduced into $500-\mathrm{ml}$ bottles closed with Viton septa and screw caps. The pollutant was added, to reach a gasphase concentration of about $6 \mathrm{mg} \mathrm{l}^{-1}$ air, unless otherwise stated. Although data are reported as gas phase concentrations, the substrate is a volatile compound and is distributed between the gas and liquid phases. As described below, biodegradation was followed by sampling the gas phase. The concentration in the liquid phase can easily be calculated based on Henry's partition coefficient. Stock cultures of the desired fungus were used as inoculum. Stock cultures were grown in mineral medium with toluene until they reached an optical density of 0.3 at $660 \mathrm{~nm}$. After homogenization, $10 \mathrm{ml}$ of that stock culture were inoculated into the bottles for the biodegradation assays, allowing all experiments to start with identical biomass concentrations and allowing the calculation of specific biodegradation rates (micrograms of toluene per gram of biomass per minute). The bottles were maintained in a thermostatic shaker at $30^{\circ} \mathrm{C}$, unless otherwise stated, with constant shaking at $200 \mathrm{rpm}$.

\section{Analytical methods}

Air samples were withdrawn from the vials under sterile conditions by means of a gastight syringe. The samples were then analyzed on a HP6890 gas chromatograph (GC) equipped with a flame ionization detector and a TR-Wax tracer column according to a method described elsewhere [18]. Carbon dioxide was measured either by a gas sensor or by gas chromatography on a HP6890 GC equipped with a thermal conductivity detector and a Porapack Q column W80/100. Samples for SEM photographs were prepared according to a previously published procedure [12].

\section{Results and discussion}

\section{Origin of the fungi and their substrate range}

The two new fungi were isolated from a biofilter that was treating alkylbenzenepolluted air. The biofilter was originally inoculated with a defined consortium described elsewhere [17], composed of a Bacillus strain, a Pseudomonas strain and the yeast Trichosporon beigelii. Its maximum elimination capacity was around $70 \mathrm{~g} \mathrm{~m}^{-3} \mathrm{~h}^{-1}$. 
However, after more than 1 year of operation, heavy fungal contamination was observed and, around that same period, the elimination capacity increased to $120 \mathrm{~g} \mathrm{~m}^{-3} \mathrm{~h}^{-1}$, with $100 \%$ removal efficiency [18]. Two fungi were isolated on toluene at the end of the second year of operation, from the highest dilutions of samples of the carrier material serially diluted in a physiological solution, composed of $0.09 \% \mathrm{NaCl}$ in distilled water. They were identified at the Centraal Bureau voor Schimmelcultures (The Netherlands) as E. oligosperma and Paecilomyces variotii, and were deposited as CBS-113408 and CBS-113409, respectively. Each organism formed a filamentous network when grown in packed-bed reactors such as gas-phase biofilters (Fig. 1a,b). This is an interesting characteristic, since it has been suggested that the growth of filamentous organisms enhances the mass transfer of hydrophobic pollutants from the gas (air) to the biocatalyst. E. oligosperma is a new, recently described, fungal species [7]. Each strain was transferred to the aqueous nutritive solution at $\mathrm{pH} 5.9$ with toluene as the sole carbon source, demonstrating their ability to use that compound as a carbon and energy source (Fig. 2). No soluble intermediate product was detected in the medium throughout the course of the biodegradation study nor after complete exhaustion of the substrate. Carbon dioxide was identified as the end-product, with an average recovery of about $65 \%$, the rest of the substrate being converted into biomass. The specific toluene biodegradation rate reached $37 \pm 3 \mu g_{\text {toluene }} \mathrm{g}^{-1} \mathrm{~min}^{-1}$ in the case of E. oligosperma, while it was only $16 \pm 2 \mu \mathrm{g}_{\text {toluene }} \mathrm{g}^{-1} \mathrm{~min}^{-1}$ with P. variotii.
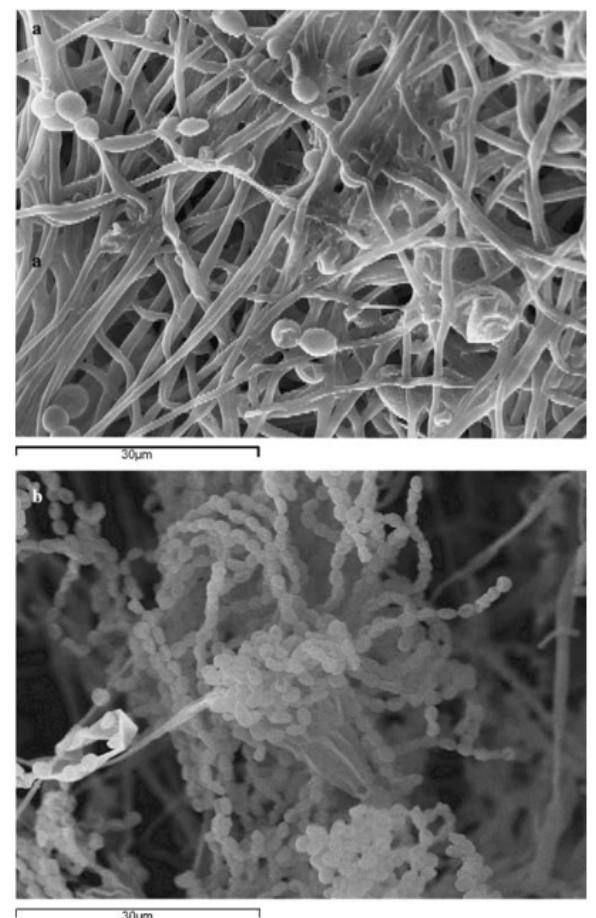

Fig. 1

SEM pictures of filter-bed samples from gas-phase packed-bed bioreactors colonized by cultures of either a E. oligosperma or b P. variotii 


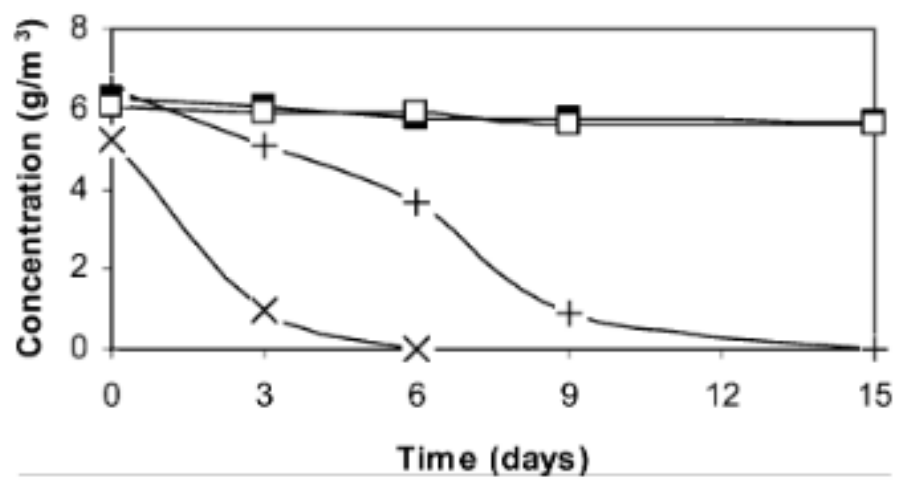

Fig. 2

Biodegradation of toluene by E. oligosperma $(\times)$ and P. variotii $(+)$ at $\mathrm{pH}$ 5.9. Data for one control (filled squares) and one blank (open squares) are also plotted

The same procedure was followed in order to check the eventual biodegradation of other benzene compounds as single substrates by the isolated fungi. The following carbon sources were tested with both isolates: benzene, ethylbenzene, o-, m-, p-xylene and styrene. None of these compounds was biodegraded. The narrow substrate range of fungi able to grow on toluene seems to be a common feature of the few species recently described in the literature [10]. So far, only one fungal strain, Cladophialophora sp. strain T1, has been shown to be able to degrade toluene, ethylbenzene and xylenes, although the xylenes were only degraded co-metabolically and were not consumed

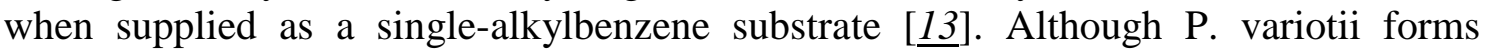
pellets when grown in aqueous phase in shake-flasks, recent studies show that each fungus produces large filaments when grown on a solid support in gas-phase biofilters [2, $\underline{3}$ ] (Fig. 1a,b). Our on-going biofiltration studies with E. oligosperma indicate that higher elimination capacities can be reached with that fungal isolate than in conventional bacteria-dominant biofilters, suggesting the advantage of using fungidominant biofilters. Indeed, preliminary data show that the elimination capacity can reach values as high as $164 \mathrm{~g} \mathrm{~m}^{-3} \mathrm{~h}^{-1}$ with that organism [3], while values ranging between approximately $10 \mathrm{~g} \mathrm{~m}^{-3} \mathrm{~h}^{-1}$ and $70 \mathrm{~g} \mathrm{~m}^{-3} \mathrm{~h}^{-1}$ are typical of conventional bacterial biofilters $[\underline{8}, \underline{9}]$.

\section{Effect of temperature on the biodegradation of toluene}

Only a few fungi can grow under thermophilic conditions [11] and none has been reported to grow on toluene at higher temperatures than about $30^{\circ} \mathrm{C}$. Most previous studies with alkylbenzenes were performed between room temperature (i.e. about $20^{\circ} \mathrm{C}$ ) and $30^{\circ} \mathrm{C}$. Since few Paecilomyces strains growing on sugars are known to be thermophilic [11], it was decided to compare the rate of toluene biodegradation at temperatures between $23^{\circ} \mathrm{C}$ and $40^{\circ} \mathrm{C}$ at $\mathrm{pH}$ 5.9. As shown in Fig. $\underline{3}$, P. variotii was able to grow on toluene over the temperature range tested. Conversely, in the case of $\mathrm{E}$. oligosperma, the rate of toluene biodegradation was relatively constant between $23^{\circ} \mathrm{C}$ and $35^{\circ} \mathrm{C}$ and was higher than with P.variotii, but dropped significantly at $40^{\circ} \mathrm{C}$ (Fig. $\underline{3}$ ). These data suggest the possibility of using fungal biofilters under slightly thermophilic 
conditions. The isolation of new thermophilic species will broaden the field of application of fungal biofilters to a wider number of pollution sources.

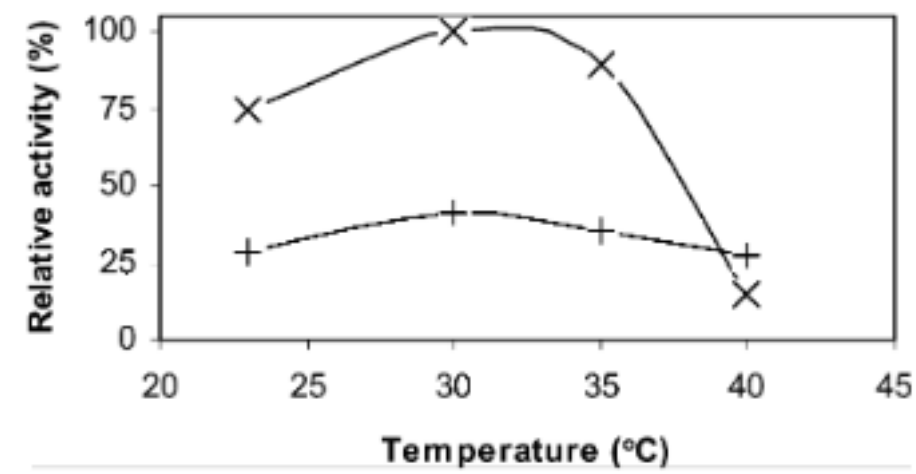

Fig. 3

Effect of temperature on the biodegradation activity of P. variotii $(+)$ and E. oligosperma $(\times)$. The highest activity reached with E. oligosperma, as mentioned in the text, is used as a reference and is normalized to $100 \%$ to allow easy comparison between the different strains and conditions

\section{Effect of $\mathrm{pH}$ on the biodegradation of toluene}

Fungi are usually relatively tolerant to acidic conditions, compared with bacteria. A set of experiments was undertaken with both fungal strains in buffered media at different $\mathrm{pH}$ values between 3.9 and 6.9. The temperature was maintained at $30^{\circ} \mathrm{C}$. In this case, both fungi degraded toluene over the whole $\mathrm{pH}$ range tested (Fig. $\underline{4}$ ). The optimum $\mathrm{pH}$ was close to 5.9. Although inhibition was somewhat more significant at the lowest $\mathrm{pH}$ for E. oligosperma than for the Paecilomyces strain, its biodegradation rate was higher at $\mathrm{pH} 3.9$ than that of P. variotii since, as mentioned above, the former strain degrades toluene at a higher rate than the latter under optimal conditions. Acidification of filter beds has sometimes been observed in biofilters used for air pollution control; and thus the development of microorganisms active under acidic conditions, such as the present fungal isolates, is a prerequisite for the successful operation of such systems.

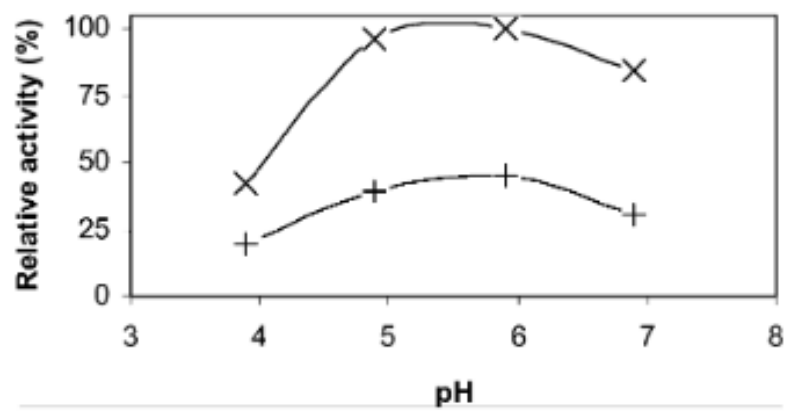

Fig. 4

Effect of $\mathrm{pH}$ on the biodegradation activity of P. variotii $(+)$ and E. oligosperma $(\times)$. The highest activity reached with E. oligosperma, as mentioned in the text, is used as areference and is normalized to $100 \%$ to allow easy comparison between the different strains and conditions

\section{Toluene degradation with different nitrogen sources}

Although both fungi can grow efficiently on toluene at low $\mathrm{pH}$, the biodegradation rates gradually decrease with lower $\mathrm{pH}$ values. As shown in the previous experiments, both 
fungi can use ammonium as their nitrogen source. Since the consumption of ammonium leads to the release of protons, the $\mathrm{pH}$ may drop in poorly buffered media or, for example, in gas-phase biofilters. This is a major concern in cases where acidification may negatively affect the performance of the reactors. Therefore, the ability to simultaneously degrade toluene and use nitrate was checked in both strains, since acidification is much less with such a nitrogen source. The results indicate that $\mathrm{E}$. oligosperma was able to use nitrate, although P. variotii was not (Fig. $\underline{5}$ ). Although the biodegradation rate of toluene in the presence of nitrate was slightly higher than with ammonium (Fig. 2), the difference was not significant.

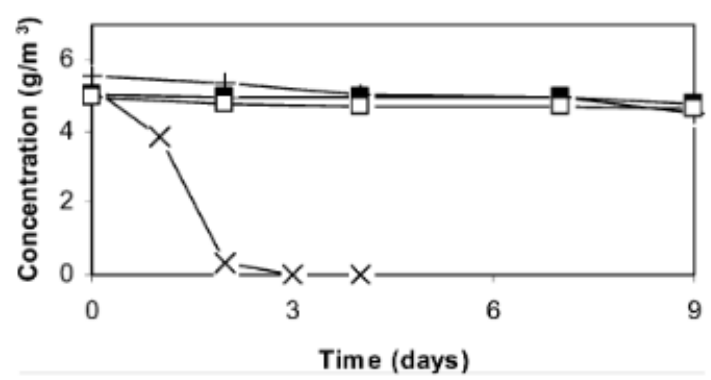

Fig. 5

Biodegradation of toluene by E. oligosperma $(\times)$ and P. variotii $(+)$ at $\mathrm{pH} 5.9$ with nitrate as single nitrogen source. Data for one control (open squares) and one blank (filled squares) are also plotted

\section{Conclusions}

- Two new fungal strains, E. oligosperma and P. variotii, were shown to use toluene as their sole carbon and energy source and to mineralize it to carbon dioxide.

- P. variotii degraded toluene at $23-40^{\circ} \mathrm{C}$, while E. oligosperma was inactive at the highest temperature of $40^{\circ} \mathrm{C}$.

- Both strains degraded toluene at pH 3.9-6.9, with an optimal activity around pH 5.9.

- E. oligosperma was able to use either ammonium or nitrate as nitrogen source in the presence of toluene, but $\mathrm{P}$. variotii used only ammonium.

\section{Acknowledgements}

The present research was financed by the Spanish Ministry of Education and Science (project CTM2004-00427).

\section{References}

1.

Agteren MH van, Keuning S, Janssen DB (1998) Handbook on the biodegradation and biological treatment of hazardous organic compounds. Kluwer, Dordrecht

2.

Estévez E, Veiga MC, Kennes C (2004) Fungal biodegradation of toluene in gas-phase biofilters. In: Verstraete (ed) Proceedings of European symposium on environmental biotechnology. Balkema, London, pp 337-340 
3.

Estévez E, Veiga MC, Kennes C (2005) Biofiltration of waste gases with the fungi Exophiala oligosperma and Paecilomyces variotii. Appl Microbiol Biotechnol (in press) 4.

García-Peña EI, Hernández S, Favela-Torres E, Auria R, Revah S (2001) Toluene biofiltration by the fungus Scedosporium apiospermum TB1. Biotechnol Bioeng 76:6169

5 .

Groenestijn JW van, Heiningen WNM van, Kraakman NJR (2001) Biofilters based on the action of fungi. Water Sci Technol 44:227-232

6.

Groenestijn JW van, Liu JX (2002) Removal of alpha-pinene from gases using biofilters containing fungi. Atmos Environ 36:5501-5508

7.

Hoog GS de, Vicente V, Caligiome RB, Kantarcioglu S, Tintelnot K, Gerrits van den Ende AHG, Hasse G (2003) Species diversity and polymorphism in the Exophiala spinifera clade containing opportunistic black yeast-like fungi. J Clin Microbiol 41:4767-4778

8.

Kennes C, Thalasso F (1998) Waste gas biotreatment technology. J Chem Technol Biotechnol 72:303-319

9.

Kennes C, Veiga MC (2001) Bioreactors for waste gas treatment. Kluwer, Dordrecht 10.

Kennes C, Veiga MC (2004) Fungal biocatalysts in the biofiltration of VOC-polluted air. J Biotechnol 113:305-319

11.

Maheshwari R, Bharadwaj G, Bhat MK (2000) Thermophilic fungi: their physiology and enzymes. Microb Mol Biol Rev 64:461-488

12.

Prado OJ, Veiga MC, Kennes C (2004) Biofiltration of waste gases containing a mixture of formaldehyde and methanol. Appl Microbiol Biotechnol 65:235-242

13.

Prenafeta-Boldú FX, Vervoort J, Grotenhuis JTC, Groenestijn JW van (2002) Substrate interactions during the biodegradation of benzene, toluene, ethylbenzene, and xylenes (BTEX) hydrocarbons by the fungus Cladophialophora sp. strain T1. Appl Environ Microbiol 68:2660-2665

14.

Prenafeta-Boldú FX, Ballerstedt H, Gerritse J, Grotenhuis JTC (2004) Bioremediation of BTEX hydrocarbons: effect of soil inoculation with the toluene-growing fungus Cladophialophora sp. strain T1. Biodegradation 15:59-65

15.

Singleton I (1994) Microbial metabolism of xenobiotics: fundamental and applied research. J Chem Technol Biotechnol 59:9-23

16.

Smith MR (1990) The biodegradation of aromatic hydrocarbons by bacteria. Biodegradation 1:191-206 
17.

Veiga MC, Fraga M, Amor L, Kennes C (1999) Biofilter performance and characterization of a biocatalyst degrading alkylbenzene gases. Biodegradation 10:169176

18.

Veiga MC, Kennes C (2001) Parameters affecting performance and modeling of biofilters treating alkylbenzene-polluted air. Appl Microbiol Biotechnol 55:254-258 19.

Weber FJ, Hage KC, Bont JAM de (1995) Growth of the fungus Cladosporium sphaerospermum with toluene as the sole carbon and energy source. Appl Environ Microbiol 61:3562-3566

20.

Woertz JR, Kinney KA, McIntosh NDF, Szaniszlo PJ (2001) Removal of toluene in a vapour-phase bioreactor containing a strain of a dimorphic yeast Exophiala lecaniicorni. Biotechnol Bioeng 75:550-558

21.

Yadav JS, Reddy CA (1993) Degradation of benzene, toluene, ethylbenzene, and xylenes (BTEX) by the lignin-degrading basidiomycete Phanerochaete chrysosporium. Appl Environ Microbiol 59:756-762 